\title{
Glucose attenuation of deficits in memory retrieval in altered light:dark cycles
}

\author{
WILLIAM S. STONE, REBECCA J. RUDD, MICHAEL E. RAGOZZINO, and PAUL E. GOLD \\ University of Virginia, Charlottesville, Virginia
}

\begin{abstract}
Previous studies in rats show that disrupting circadian light-dark rhythms leads to impairments in memory. In particular, both phase delays and phase advances of the light:dark cycle initiated after inhibitory (passive) avoidance training result in impaired retention. The present study examined this phenomenon in mice and, using a retrieval design, examined whether glucose or epinephrine could attenuate deficits in memory. Groups of mice were first trained on an inhibitory avoidance task during the light portion of the illumination cycle. They were then maintained for a 72-h train-test interval either under the same schedule of illumination or one with a phase advance of $4 \mathrm{~h}$. Thirty minutes before testing, groups were injected with saline, glucose $(1,10,100,250$, or $500 \mathrm{mg} / \mathrm{kg})$, or epinephrine $(0.1 \mathrm{mg} / \mathrm{kg})$. The results showed that (1) retention was significantly impaired in phase-shifted mice relative to nonphase-shifted controls and (2) both glucose $(100 \mathrm{mg} / \mathrm{kg})$ and epinephrine attenuated the deficit in memory. These findings indicate that altered illumination schedules disrupt memory in mice as well as in rats. In addition, they suggest that glucose may be a useful treatment to attenuate deficits in memory associated with impaired biological rhythms.
\end{abstract}

Biological rhythms influence a wide variety of systems and functions in living organisms, including cognitive functions such as memory (e.g., Folkard, Wever, \& Wildgruber, 1983; Leconte, 1989). For example, rats maintained in 12:12-h light:dark cycles show systematic variations in retention at different times of day. In several tasks, such as inhibitory (passive) avoidance, active avoidance, and one-trial appetitive maze learning, retention varies systematically over circadian periods, with performance peaks occurring at 12-h intervals (Davies, Navaratnam, \& Redfern, 1973; Holloway \& Wansley, 1973; Wansley \& Holloway, 1975). Similarly, the effectiveness of posttraining treatments that either impair (e.g., electroconvulsive shock) or facilitate (e.g., strychnine) memory for inhibitory avoidance varies over 24-h periods (Stephens \& McGaugh, 1968; Stephens, McGaugh, \& Alpern, 1967; Wenzel, 1981).

The manipulation of biological rhythms further demonstrates their influence on memory. Rats trained on inhibitory or active avoidance tasks and then subjected to phase shifts in the illumination schedule show subsequent deficits in retention when tested 1-7 days after training (Davies, Navaratnam, \& Redfern, 1974; Fekete, van Ree, Niesink, $\&$ de Wied, 1985; Fekete, van Ree, \& de Wied, 1986; Tapp \& Holloway, 1981). These retention deficits appear after both phase advances and phase delays of several

This research was supported by grants from the National Institutes on Aging (AG 07648), the Office of Naval Research (NO01489-J-1216), and the National Science Foundation (BNS-9012239) to P.E.G. W.S.S. was the recipient of an NRSA (AG 05408). Address correspondence to W. S. Stone, Department of Psychology, University of Virginia, Gilmer Hall, Charlottesville, VA 22903. hours, and occur regardless of whether retention is assessed in the same portion of the light:dark cycle (i.e., the light or dark period) as when training occurs (the light period).

Few studies have examined how disruption of circadian organization affects specific processes of memory. Fekete et al. (1985) found that retention deficits for inhibitory avoidance appeared when rats were phase shifted before testing but not when the shift was introduced immediately after training. They also found that pharmacological treatments (with ORG 2766, an ACTH analog, and with vasopressin) administered before testing attenuated the deficits in retention. The present study employs a similar design, in which the light:dark cycle is phase shifted forward by $4 \mathrm{~h}$ after inhibitory avoidance training, to determine whether additional treatments can also attenuate deficits in memory produced by altered circadian rhythms.

A large body of evidence from this and other laboratories established that epinephrine modulates memory storage in a variety of conditions (cf. Gold, 1991). Because epinephrine is largely excluded from the CNS, we hypothesized that one of its peripheral actions, the release of glucose, might mediate its subsequent effects on memory and other CNS functions. Numerous findings obtained over the last several years provide support for this interpretation and show that glucose enhances memory in rodents and humans when administered pre- or posttraining (cf. Gold, 1991). In addition, we recently found that glucose enhances memory retrieval (Stone, Rudd, \& Gold, 1990). The present study examines whether glucose, administered before testing, can enhance memory retrieval in mice subjected to an altered lighting schedule after inhibitory avoidance training. For comparison with another 
treatment that enhances memory, mice will also be tested with epinephrine.

\section{METHOD}

\section{Subjects}

Six-week-old male mice (DUB-ICR, Dominion Laboratories, Dublin, VA) were housed in groups of 4 , with free access to food and water throughout the experiment. All mice were maintained on a 12:12-h light:dark cycle (lights on at $0600 \mathrm{~h}$, or as indicated in the procedure). Behavioral testing was performed between 1200 and $1300 \mathrm{~h}$.

\section{Procedure}

The mice were trained to a criterion on an inhibitory (passive) avoidance task. The training apparatus consisted of a two-compartment chamber in which a lighted start compartment $(10 \times 14 \times 23 \mathrm{~cm})$ was separated from a larger dark compartment $(10 \times 14 \times 37 \mathrm{~cm})$ by a sliding door. The training procedure was similar to that of Stone et al. (1990). At the start of a trial, the mice were placed in the lighted compartment, the sliding door was opened, and the latency to enter the dark compartment (all four paws) was recorded. The animals then received an escapable footshock $(0.3 \mathrm{~mA})$ through metal plates that constituted the floor of the compartment. When the mice reentered the lighted start compartment, the shock was turned off. Each mouse received training until it did not reenter the dark compartment within $90 \mathrm{sec}$, then it was removed from the apparatus. About $50 \%$ of the mice were trained in one trial, and $50 \%$ required two trials. The number of training trials required was randomly distributed across treatment conditions. All mice included in the experiment showed latencies of $60 \mathrm{sec}$ or less to cross into the dark compartment on the initial trial (preshock).

Seventy-two hours after training, the mice were tested for retention of the avoidance behavior. The testing and training procedures were identical except that no shock was administered when the animals crossed over into the dark compartment. Latencies to enter the dark compartment were recorded to a maximum of $600 \mathrm{sec}$. Thirty minutes before testing, groups of mice received saline, glucose $(1,10,100$, 250 , or $500 \mathrm{mg} / \mathrm{kg}$ ), or epinephrine $(0.1 \mathrm{mg} / \mathrm{kg}$ ). Glucose (D-glucose, J. T. Baker Chemical Co.) and epinephrine (epinephrine bitartrate, Sigma Chemical Co.) were dissolved in saline and injected i.p. on each experimental day. The dose of epinephrine was selected on the basis of previous studies that showed that it facilitates memory for inhibitory avoidance in rodents (cf. Gold, 1991). Comparisons between groups were performed using Mann-Whitney $U$ tests (two tailed). The training and testing procedures were performed by an observer blind to the hypotheses being tested.

All mice were trained under the original lighting schedule (lights on at $0600 \mathrm{~h}$ ), and all training occurred in the light portion of the light:dark cycle (1200-1300 h). After training, one group of mice was maintained under the original light-dark schedule until testing $(72 \mathrm{~h})$. All other groups were exposed to an altered light-dark schedule characterized by a 4-h phase advance (i.e., lights off at $1400 \mathrm{~h}$ ) that started about $1 \mathrm{~h}$ after training and continued until testing $(72 \mathrm{~h})$. Testing and training were performed at the same time of day and in the light portion of the light:dark cycle.

The experiment was performed on batches of 10-20 mice per session. As a check on the validity of the pharmacological treatments, each batch included mice from saline control groups in addition to mice from different treatment conditions. The control groups therefore contained more mice than did the treatment groups.

\section{RESULTS}

Figure 1 shows that saline-treated mice exposed to the altered light-dark schedule had significantly lower inhibitory avoidance latencies than mice continuously exposed to the original light-dark schedule (Mann-Whitney $U=$ $101.5, p<.02)$. Figure 1 also demonstrates that glucose

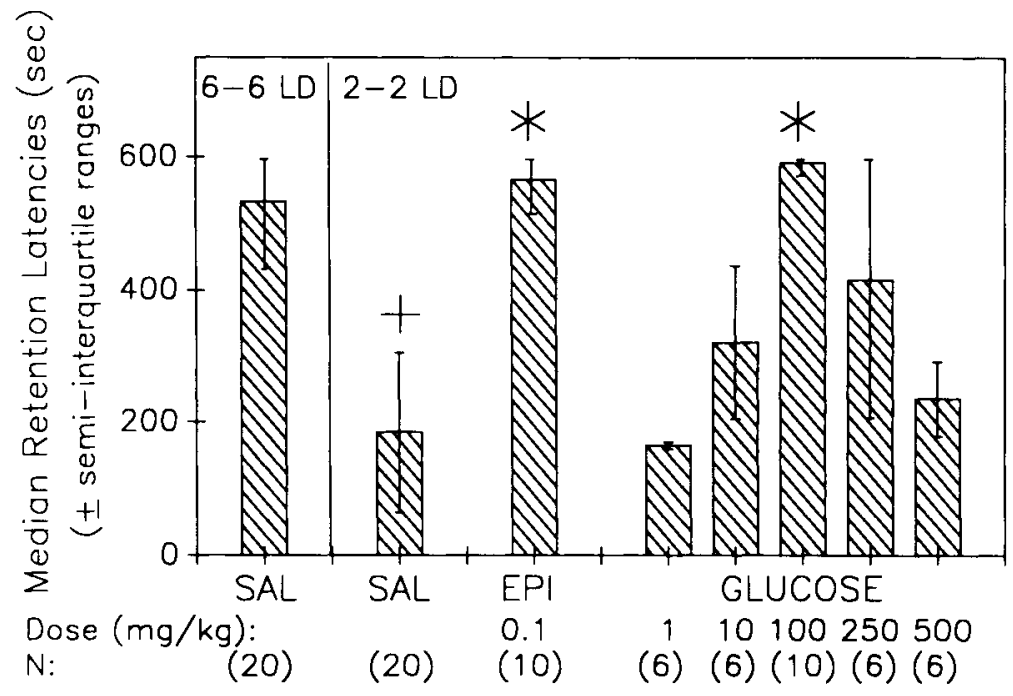

Figure 1. Retention performance of mice trained to criterion in a multitrial inhibitory avoidance task $(0.3 \mathrm{~mA})$ and tested for retention $72 \mathrm{~h}$ later. After training, mice were maintained on either the original 0600-0600-h (6-6) or a phaseshifted 1400-1400-h (2-2) illumination schedule. Mice in the phase-shifted schedule had significantly lower latencies (poorer retention) than did nonphase-shifted controls. The deficits were reversed in groups of mice that received injections of epinephrine $(0.1 \mathrm{mg} / \mathrm{kg})$ or glucose $(100 \mathrm{mg} / \mathrm{kg}) . \quad{ }^{p} p<.02$ compared with nonphase-shifted saline control group. * $p<.05$ compared with phase-shifted saline group. 
$(100 \mathrm{mg} / \mathrm{kg})$ and epinephrine $(0.1 \mathrm{mg} / \mathrm{kg})$ administered prior to testing significantly enhanced retention $\left(U_{\mathrm{s}}=37.5\right.$ and 51.5, respectively; $p s<.05$ ). The effects of glucose on retrieval followed an inverted- $U$ dose-response curve.

\section{DISCUSSION}

In agreement with previous studies (Davies et al., 1974; Fekete et al., 1985, 1986; Tapp \& Holloway, 1981), these results show that a phase shift in the circadian illumination schedule introduced between training and testing periods results in impaired retention of inhibitory avoidance behavior. These findings also indicate that retention in mice, as well as rats, is disrupted after alterations of the light:dark cycle. More generally, these results confirm and extend previous evidence that biological rhythms exert a robust influence on memory for inhibitory avoidance. For example, the values of several parameters used in this study to produce retention deficits after alterations of the light:dark cycle are representative of a range of values previously found to be effective. Among these are the direction and extent of the phase alteration. While a 4-h phase advance was effective in the present procedure, 4- to 6-h phase advances or delays also result in memory deficits, as does a 12-h phase reversal or a switch to a constantlight condition. Similarly, deficits in retention observed in this study after a 3-day exposure to altered lighting occur with exposure times lasting 1-7 days. In addition, the effect occurs across tasks (inhibitory and active avoidance), species (rats and mice), and portions of the light:dark cycle (i.e., performance is not dependent on whether animals are tested in the light or dark portion of the illumination schedule).

Few studies have examined the neurobiological mechanisms underlying the retention deficit, but they suggest that the effects of altered lighting are relatively selective and are related to disruption of biological hythms. Fekete et al. (1985) found that the altered illumination schedule did not change several aspects of exploratory or social activity, as it did memory. Tapp and Holloway (1981) found that memory for inhibitory avoidance after lighting alterations differed in individual animals and was related to the reentrainment patterns of the circadian activity rhythm. Greater disruption of the activity rhythm was associated with poor memory, and less disruption was associated with good memory.

Both glucose and epinephrine reversed the effects of the altered light:dark cycle on memory, using a pretesting (retrieval) design. These findings extend those of a previous study that showed that glucose and epinephrine enhanced retrieval for inhibitory avoidance in normal, unimpaired rats and mice (Stone et al., 1990). More broadly, these results provide further evidence that glucose attenuates impairments in memory caused by several conditions. Among these, glucose attenuates memory deficits produced by several amnestic treatments, including scopolamine, morphine, an NMDA antagonist, and amygdaloid kindling (cf. Gold, 1991). Glucose also improves memory in rodents and humans in naturally occurring conditions associated with retention deficits, such as aging (cf. Gold, 1991).

As in previous studies with glucose, epinephrine, and other treatments that modulate memory (cf. Gold, 1989, 1991), an inverted- $U$ dose-response curve was obtained for glucose. Enhancement of memory thus appears to be generally well regulated within neurobiological boundaries, as shown by the relative ineffectiveness of higher and lower doses. Among other possibilities, the failure of higher-thanoptimal doses to enhance memory may reflect a saturation and functional blockade of neurobiological substrates involved in memory modulation, or it may reflect activation of compensatory counterregulatory mechanisms.

Biological thythms, impaired either transiently (e.g., " "jet lag") or chronically (e.g., aging), may be physiologically deleterious (cf. Brock, 1991) and often occur in parallel with impaired cognitive functions (Graeber, 1982; Stone, 1989). The deficits in memory found in this and other studies after alterations of biological rhythms suggest that altered biological rhythms in other conditions may similarly contribute to impaired memory. For example, various rhythms in old age demonstrate a trend toward internal desynchronization (cf. Monk, 1989). Performance on cognitive tasks, including measures of memory, normally covaries with circadian measures such as the sleep-wake and body-temperature cycles (e.g., Tilley \& Warren, 1983; cf. Monk, 1989), which suggests the possibility that impaired rhythms may contribute to impaired cognition in old age. The present findings, along with previous evidence that glucose enhances memory in old age (Hall, GonderFrederick, Chewning, Silveira, \& Gold, 1989; Manning, Hall, \& Gold, 1990; Stone, Rudd, \& Gold, 1992), suggest the view that glucose may attenuate memory impairments associated with disturbed biological rhythms in a variety of conditions.

\section{REFERENCES}

Brock, M. A. (1991). Chronobiology and aging. Journal of the American Geriatric Society, 39, 74-91.

Davies, J. A., Navaratnam, V., Redfern, P. H. (1973). A 24 hour thythm in passive-avoidance behavior in rats. Psychopharmacologia, 32, 211-214.

Davies, J. A., Navaratnam, V., Redfern, P. H. (1974). The effect of phase-shift on the passive avoidance response in rats and the modifying action of chlordiazepoxide. British Journal of Pharmacology, 51, 447-451.

Fekete, M., van Ree, J. M., de Wied, D. (1986). The ACTH(4-9) analog ORG 2766 and desglycinamide ${ }^{9}$-( arg $\left.^{6}\right)$-vasopressin reverse the retrograde amnesia induced by disrupting circadian thythms in rats. Peptides, 7, 563-568.

Fekete, N., VAN ReE, J. M., Niestnk, R. J. M., \& DE Wied, D. (1985). Disnupting circadian rhythms in rats induces retrograde amnesia. Physiology \& Behavior, 34, 883-887.

Folkard, S., Wever, R. A., Wildgruber, C. M. (1983). Multioscillatory control of circadian rhythms in human performance. $\mathrm{Na}$ ture, 305, 223-226.

Gow, P. E. (1989). Neurobiological features common to memory modulation by many treatments. Animal Learning \& Behavior, 17, 94-100. 
GoLD, P. E. (1991). An integrated memory system: From blood to brain. In R. C. A. Frederickson, J. L. McGaugh, \& D. L. Felton (Eds.), Peripheral signaling of the brain: Role in neural-immune interactions, learning and memory (pp. 391-419). Toronto: Hogrefe \& Huber.

GRAEBER, R. C. (1982). Alterations in performance following rapid transmeridian flight. In F. M. Brown \& R. C. Graeber (Eds.), Rhythmic aspects of behavior (pp. 173-211). Hillsdale, NJ: Erlbaum.

Hall, J. L., Gonder-Frederick, L. A., Chewning, W. W., SilVEIRA, J., \&OLD, P. E. (1989). Glucose enhancement of memory in young and aged humans. Neuropsychologia, 27, 1129-1138.

Holloway, F. A., \& WANSLEY, R. A. (1973). Multiple retention deficits at periodic intervals after active and passive avoidance learning. $B e$ havioral Biology, 9, 1-14.

LeConte, P. (1989). Chronobiological thythm constraints of memory processes. Archives of Gerontology \& Geriatrics, Suppl. 1, 21-35.

Manning, C. A., Hall, J. L., \& Gold, P. E. (1990). Glucose effects on memory and other neuropsychological tests in elderly humans. Psychological Science, 5, 307-311.

Monk, T. (1989). Circadian thythm. Clinics in Geriatric Medicine, 5, 331-346.

STEPHENS, G., \& MCGAugh, J. L. (1968). Retrograde amnesia effects of periodicity and degree of training. Part A. Communications in Behavioral Biology, 1, 267-275.

Stephens, G., MCGaugh, J. L., \& AlPern, H. P. (1967). Periodicity and memory in mice. Psychonomic Science, 8, 201-202.
Stone, W. S. (1989). Sleep and aging in animals: Relationships with circadian rhythms and memory. Clinics in Geriatric Medicine, 5 , 363-379.

Stone, W. S., Rudd, R. J., \& Gold, P. E. (1990). Amphetamine, epinephrine, and glucose enhancement of memory retrieval. Psychobiology, 18, 227-230.

Stone, W. S., RUDD, R. J., \& Gold, P. E. (1992). Glucose attenuates deficits in memory and increases $\left[{ }^{3} H\right] 2$-deaxy-D-glucose in scopolaminetreated and old mice. Manuscript submitted for publication.

TAPP, W. N., Holloway, F. N. (1981). Phase shifting circadian rhythms produces retrograde amnesia. Science, 211, 1056-1058.

TILley, A., WarReN, P. (1983). Retrieval from semantic memory at different times of day. Joumal of Experimental Psychology: Learming, Memory, \& Cognition, 9, 718-724.

Wansley, R. A., \& Holloway, F. A. (1975). Multiple retention deficits following one-trial appetitive training. Behavioral Biology, 14, 135-149.

WENZEL, Z. M. (1981). Differential facilitation of memories by strychnine at different times of day. Behavioral \& Neural Biology, 33, 498-502.

(Manuscript received August 16, 1991; revision accepted for publication January 13, 1992.)

\title{
Nominations for the Editorship of Memory \& Cognition
}

Nominations are solicited for the editorship of Memory \& Cognition. The term of the present editor, Margaret Jean Intons-Peterson, expires at the end of 1993. The new editor will begin an official 4-year term January 1, 1994, and will begin to receive manuscripts early in January 1993. It is expected that the Publications Committee of the Psychonomic Society will make the appointment by July 1992 .

Nominations must be submitted by April 15, 1992.

Nominations (including self-nominations) should be sent to:

\author{
Alice F. Healy \\ Department of Psychology \\ University of Colorado \\ Campus Box 345 \\ Boulder, CO 80309-0345
}

\section{Nominations for the Editorship of Perception \& Psychophysics}

Nominations are solicited for the editorship of Perception \& Psychophysics. Charles W. Eriksen, who has been the editor since 1971, will be retiring in 1993. The new editor will begin an official 4-year term January 1, 1994, and will begin to receive manuscripts early in 1993. It is expected that the Publications Committee of the Psychonomic Society will make the appointment by July 1992.

Nominations must be submitted by April 15, 1992.

Nominations (including self-nominations) should be sent to:
Anne M. Treisman
Russell Sage Foundation
112 East 64th Street
New York, NY 10021 